
\title{
The Lymphocyte Depletion in Patients with Acute Ischemic Stroke Associated with Poor Neurologic
} Outcome

\author{
Cep Juli ${ }^{1,2}$ \\ Henhen Heryaman' \\ Arnengsih Nazir \\ Eng-Tat Ang ${ }^{3}$ \\ Irma Ruslina Defi ${ }^{4}$ \\ Uni Gamayani ${ }^{2}$ \\ Nur Atik (iD ${ }^{5}$ \\ 'Doctoral Program, Faculty of Medicine, \\ Padjadjaran University, Bandung, \\ Indonesia; ${ }^{2}$ Department of Neurology, \\ Dr. Hasan Sadikin General Hospital, \\ Faculty of Medicine, Padjadjaran \\ University, Bandung, Indonesia; \\ ${ }^{3}$ Department of Anatomy, Yong Loo Lin \\ School of Medicine, National University \\ of Singapore, Singapore; ${ }^{4}$ Department of \\ Physical Medicine and Rehabilitation, \\ Dr. Hasan Sadikin General Hospital, \\ Faculty of Medicine, Padjadjaran \\ University, Bandung, Indonesia; \\ ${ }^{5}$ Department of Biomedical Sciences, \\ Faculty of Medicine, Padjadjaran \\ University, Bandung, Indonesia
}

Correspondence: Nur Atik Department of Biomedical Sciences, Faculty of Medicine, Padjadjaran University, Bandung, Indonesia Email n.atik@unpad.ac.id
Purpose: Inflammation plays an important role and is involved in all stages of acute ischemic stroke. One of these stages involves the recruitment of leukocytes from the peripheral circulation into the ischemic tissue. Lymphocytes as a subtype of leukocytes are important mediators and can become a predictor of neurological outcome. Several studies have been conducted regarding the correlation between differential lymphocyte counts and acute ischemic stroke. Most of these studies analyzed lymphocyte ratio to other leukocyte subtypes such as neutrophils and monocytes. This study specifically observed the role of lymphocytes as an indicator of the inflammatory response in patients with acute ischemic stroke. This study aimed to observe the correlation among risk factors, infarct location, leukocyte counts, lymphocyte value and neurologic output in acute ischemic stroke patients. Patients and Methods: We observed and analyzed 193 patients' data from medical record which met the inclusion and exclusion criteria with a diagnosis of acute ischemic stroke at the Department of Neurology of Dr. Hasan Sadikin General Bandung. Data were then analysed using appropriate statistical tests.

Results: Most patients have more than one risk factor with a leukocyte count of less than $10,000 \mathrm{cell} / \mathrm{mm}^{3}$. Infarct was mostly located in subcortical area (basal ganglia), with moderate average NIHSS values at admission and at discharge. The number of lymphocytes decreased in the subject group with more than 10,000 cell $/ \mathrm{mm}^{3}$ leukocytes. Subsequently, data were analyzed using Spearman's test and there was a correlation between NIHSS on admission and lymphocyte depletion.

Conclusion: The lymphocyte depletion in patients with leukocytosis is a predictor of poor NIHSS.

Keywords: ischemic stroke, lymphocyte depletion, poor neurologic outcome

\section{Introduction}

Stroke ranks first as the global cause of disability. ${ }^{1}$ Of all stroke cases, ischemic stroke contributes $85 \%$ of the cases with thrombotic stroke as the main pathologic feature. ${ }^{1,2}$ Thrombotic stroke may be located in the main arteries or branches of the cortical arteries, subcortical regions, brainstem, or cerebellum. In thrombotic-type strokes, the main underlying process is atherosclerosis. ${ }^{1,3,4}$

Atherosclerotic lesions which process is the main cause occlusion of the large arteries occur more easily in individuals with risk factors such as hypertension, dyslipidemia, diabetes mellitus, and smoking. ${ }^{1,4,5}$ In this process, endothelial blood vessel damage results in oxidation and release of inflammatory mediators. ${ }^{1,6}$ 
Currently, there is increasing evidence that the mechanism of inflammation plays a role in the development and progression of ischemic stroke. Immune system is involved at all levels of the ischemic cascade. Inflammation occurs by both molecular and cellular components on the surface of blood microvascular endothelial cells. ${ }^{1,7,8}$ Pathological features in ischemic stroke, such as cell necrosis, debris produced by dead cells, and reactive oxygen species (ROS), may induce inflammation in nerve cells through activation of microglia and astrocytes, as well as infiltration of leukocytes from peripheral blood circulation. ${ }^{9,10}$

The pathophysiology of lymphocyte activity in post stroke is not characterized yet, and also the other subtypes of leukocytes, i.e neutrophils and monocytes. ${ }^{10,11}$ It is stated that the role of lymphocytes in acute ischemic stroke is still controversial. Lymphocytes infiltrate the ischemic tissue and mediate the inflammatory response, where it may increase the level of antiinflammatory cytokines and suppress the production of proinflammatory cytokines. During ischemic stroke cascade, infiltration of immune cells and the release of proinflammatory cytokines are included in secondary development of neuronal injury, which decreases bloodbrain barrier impairment, brain edema, and infarct volume. ${ }^{12}$ In patients with acute ischemic stroke, the number of lymphocytes was often observed to be reduced. Several studies have shown that a low lymphocyte count is associated with poor clinical neurological outputs and plays a negative role in long-term functional recovery. ${ }^{10,11}$

The National Institute of Health Stroke Scale (NIHSS) has been used in most studies on acute strokes to evaluate the neurological outputs. The NIHSS is a stroke-specific quantitative scale that examines the level of consciousness, language function, neglect, visual fields, eye movements, facial symmetry, motor strength, sensation, and coordination. The range of NIHSS score varies from 0 to 42 . A lower NIHSS score during the initial phase of acute ischemic stroke independently correlates with good neurological outputs. ${ }^{13-15}$

Without discounting the importance of the other leucocytes (eg neutrophils, and monocytes), there should be a concerted effort to understand the importance of lymphocytes in the context of ischemic stroke. The study aims to observe the role of lymphocytes and correlate it to the other risk factors, leukocyte count and neurologic output in patients with acute ischemic stroke.

\section{Patients and Methods}

\section{Subject Selection and Study Design}

This was a cross-sectional observational analytical study using retrospective data. Secondary data from 193 subjects in the form of medical records of patients treated at the Department of Neurology of Dr. Hasan Sadikin General Bandung for ischemic stroke (November 2018 to October 2019) were used.

The inclusion criteria were acute ischemic stroke in patients who were not treated with thrombolysis and thrombectomy. Stroke was defined as a neurological deficit that begins abruptly with acute focal injury by vascular disease persisting $\geq 24$ hours and was proven by objective evidence. ${ }^{16,17}$ The type of stroke was classified according to the TOAST classification, including large artery atherosclerosis, small artery occlusion, cardioembolism, other demonstrated cause, and undetermined cause (cryptogenic), ${ }^{3}$ whereas the subtype of stroke within the inclusion criteria were large artery atherosclerosis and small artery occlusion. Stroke severity was stratified on the basis of NIHSS score as follows: 1-4 mild, 5-15 moderate, and more than 15 was severe stroke. ${ }^{13-15}$

Laboratory assessment for analyzing the risk factor such as fasting venous blood samples, lipid profile, blood glucose levels, uric acid and blood test for cell counts were done on admission to the hospital before the treatment. CT head scan without contrast showing infarction that matched the thrombotic features (atherothrombotic, thromboembolic and lacunar)]. ${ }^{1,3,4}$ Location within the basal ganglia, internal capsule, or corona radiata with a diameter between 15 and $40 \mathrm{~mm}$ suggests diagnosis for large subcortical infarct, whereas diameter of $15 \mathrm{~mm}$ in the same location addressed as small deep infarcts. Superficial ischemic lesions in the territory of one of the large major cerebral arteries or lesions in a border zone were called cortical infarcts, while the underlying white matter might be involved as well. ${ }^{18}$

The exclusion criteria were a history of autoimmune diseases, the use of immunosuppression drugs, the presence of infection (excluded with clinical signs and symptoms such as abnormal body temperature, respiratory problems and also supporting examinations such as blood tests and chest X-rays), any haematological disorders, malignancy, kidney and liver disease, and features of bleeding and cardioembolic infarction on CT scan as follow, wedge shape infarction based in the cortex, acute bilateral infarctions, location of infarction in the anterior 
and posterior circulation, multiple cortical infarction in various vascular distribution, and greater tendency to hemorrhagic transformation. ${ }^{16,19,20}$

Each patient record was coded anonymously to ensure confidentiality during statistical analysis. The protocol study was approved by the Padjadjaran University Ethics Research Committee (No. 1554/UN6.KEP/EC/2019) and conducted in compliance with the Declaration of Helsinki.

\section{Statistical Analysis}

Categorical data are presented in number, frequency and percentage, while numerical data are presented in mean, median, standard deviation, and range. Data distribution was evaluated using the Kolmogorov Smirnov test. For numerical comparison of two groups of data, $T$-test was used for normally distributed data. Mann-Whitney test analysis was used if data were not normally distributed. The significance tests used for more than two groups were one-way ANOVA, if data were normally distributed and the variance was homogeneous, and the Kruskal Wallis test if not normally distributed. Correlation between numerical data were done using Pearson or Spearman test.

\section{Results}

This study successfully collected data from 193 ischemic stroke patients, with 98 males $(50.8 \%)$ with age mostly $<60$ years old $(65.3 \%)$. Several risk factors for ischemic stroke were identified from the study subjects, such as hypertension, dyslipidemia, diabetes mellitus, smoking, hyperuricemia, age and previous stroke history. The most common risk factor identified was hypertension in 177 $(88.5 \%)$ patients followed by dyslipidemia in 110 $(55.0 \%)$, previous stroke history $77(38.5 \%)$, age 70 (35.0\%), diabetes mellitus $56(28.0 \%)$, smoking 36 (18.0\%) and hyperuricemia $16(8.0 \%)$. Most subjects had more than one risk factor $(n=175,90.7 \%)$. We cannot collect past medication history from the patients because poor compliance and awareness of the patients, the patient forgot the medicine that was taken and the data in medical records were incomplete.

During the acute phase of stroke ischemia, the patients were given anti aggregation platelet, anti hypertension and diabetic therapy, cholesterol and uric acid lowering medication, depend on the risk factors that they had. The management was in accordance with widely used guidelines in neurology, such as aspirin which was the choice for anti-aggregation platelets and statin therapy in patients with dyslipidemia. $^{21,22}$
The average leukocyte count during treatment was $9337.01 \pm 2835.22$ with most having $\leq 10,000$ leukocytes $(65.8 \%)$. The differential lymphocyte count was also analyzed and showed an average of $20.97 \pm 10.126$ in subjects with more than one risk factor. Ischemic stroke was mostly located in the subcortical area, which was found in 156 subjects $(80.8 \%)$ with 98 of them located in the basal ganglia (62.8\%). The average NIHSS at admission was $6.49 \pm 3.20$ while the average NIHSS score at discharge was $5.44 \pm 2.93$. Most patients were in moderate NIHSS degree, both at admission and at discharge, with $62.7 \%$ and $56.5 \%$, respectively (Table 1 ).

The comparison of lymphocyte counts between risk factors using Mann-Whitney test revealed that there was no significant difference $(\mathrm{P}>0.05)$ (Table 2$)$. When lymphocyte counts and leukocyte level were compared, it showed statistically significant results with a $\mathrm{P}$ value of less than $0.05(\mathrm{P}<0.05)$ (Table 3$)$. The statistical analysis on the relationship between lymphocytes and the location of infarction resulting in insignificant results $(\mathrm{P}>0.05)$ (Table 4) We also analyzed the correlation between neutrophil lymphocyte ratio and NIHSS score, however both statistical analysis did not show any correlation. Finally, we analyzed the correlation between lymphocyte and NIHSS score using using Spearman's test and showed a significant correlation with a $\mathrm{P}$ value of less than 0.05 $(\mathrm{P}<0.05)$ (Table 5).

\section{Discussion}

The conventional theory of atherosclerosis as a disease caused by fat deposits has been challenged with the growing evidence that inflammation is involved in all stages of atherosclerosis, starting from the initial injury to thrombotic complications as the late stage. ${ }^{23}$ Endothelial responses are seen in the form of increased expression of cellular adhesion molecules and proinflammatory cytokines in atherosclerotic lesions which increases leukocyte accumulation and activation. ${ }^{24,25}$ Leukocytosis has been linked to the degree of atherosclerotic disease. In addition, leukocytosis is associated with unstable plaque and is also seen as a factor that induces acute thrombotic events. ${ }^{26}$

Narrowing of the arteries due to atherosclerosis most often occurs in the internal carotid artery and its branches. These arteries are the main blood vessels that affect important structures in the cortical and subcortical regions. Carotid blood vessels become predilected in atherosclerosis due to blood flow patterns in the area where there are hemodynamic variations, such as shear stress, which 
Table I Demographic Characteristics, Risk Factor, Leukocyte Count, Differential Leukocyte Count, Infarct Location, and NIHSS

\begin{tabular}{|c|c|}
\hline Variables & $N=193$ \\
\hline \multicolumn{2}{|l|}{ Gender } \\
\hline Male & $98(50.8 \%)$ \\
\hline Female & 95 (49.2\%) \\
\hline \multicolumn{2}{|l|}{ Age } \\
\hline$<60$ years & 126 (65.3\%) \\
\hline$\geq 60$ years & 67 (34.7\%) \\
\hline \multicolumn{2}{|l|}{ Risk factor } \\
\hline I Risk factor & $18(9.3 \%)$ \\
\hline$\geq 2$ risk factors & I 75 (90.7\%) \\
\hline \multicolumn{2}{|l|}{ Leukocyte (cells/uL) } \\
\hline Mean \pm Std & $9337.01 \pm 2835.224$ \\
\hline Median & 9110.00 \\
\hline Range (min-max) & $516.00-19,140.00$ \\
\hline \multicolumn{2}{|l|}{ Basophil (\%) } \\
\hline Mean \pm Std & 0.00 \\
\hline Median & 0.00 \\
\hline Range (min-max) & 0.00 \\
\hline \multicolumn{2}{|l|}{ Eosinophil (\%) } \\
\hline Mean \pm Std & $1.60 \pm 2.096$ \\
\hline Median & 1.00 \\
\hline Range (min-max) & $0.00-13.00$ \\
\hline \multicolumn{2}{|l|}{ Banded neutrophil (\%) } \\
\hline Mean \pm Std & $0.04 \pm 0.311$ \\
\hline Median & 0.00 \\
\hline Range (min-max) & $0.00-3.00$ \\
\hline \multicolumn{2}{|l|}{ Segmented neutrophil (\%) } \\
\hline Mean \pm Std & $69.93 \pm 12.652$ \\
\hline Median & 70.00 \\
\hline Range (min-max) & $7.00-94.00$ \\
\hline \multicolumn{2}{|l|}{ Lymphocyte (\%) } \\
\hline Mean \pm Std & $20.87 \pm 9.944$ \\
\hline Median & 20.00 \\
\hline Range (min-max) & $4.00-52.00$ \\
\hline \multicolumn{2}{|l|}{ Monocyte (\%) } \\
\hline Mean \pm Std & $7.25 \pm 3.281$ \\
\hline Median & 7.00 \\
\hline Range (min-max) & $1.00-26.00$ \\
\hline \multicolumn{2}{|l|}{ Neutrophil Lymphocyte Ratio } \\
\hline Mean \pm Std & $4.81 \pm 3.912$ \\
\hline Median & 3.45 \\
\hline Range (min-max) & $0.50-23.50$ \\
\hline
\end{tabular}

(Continued)
Table I (Continued).

\begin{tabular}{|l|c|}
\hline Variables & $\mathbf{N}=193$ \\
\hline Infarct location & \\
Subcortical & $156(80.8 \%)$ \\
Cortical & $22(11,4 \%)$ \\
Pons & $15(7.8 \%)$ \\
\hline NIHSS at admission & \\
Mean \pm Std & $6.49 \pm 3.200$ \\
Median & 6.00 \\
Range (min-max) & $1.00-19.00$ \\
\hline NIHSS degree at admission & \\
Mild & $66(34.2 \%)$ \\
Moderate & $121(62.7 \%)$ \\
Severe & $6(3.1 \%)$ \\
\hline NIHSS at discharge & \\
Mean \pm Std & $5.44 \pm 2.925$ \\
Median & 5.00 \\
Range (min-max) & $0.00-16.00$ \\
\hline NIHSS degree at discharge & \\
Mild & $109(56.5 \%)$ \\
Moderate & $1(0.5 \%)$ \\
Severe & \\
\hline
\end{tabular}

strongly influence the process of atherosclerosis and the remodeling in these vessels. ${ }^{16,27}$

In acute ischemic stroke, tissue hypoxia induces an inflammatory reaction in the brain parenchyma. There is an increase in the number of peripheral vascular leukocytes is seen in the first 72 hours after onset. Infiltrated leukocytes cause cerebral ischemic injury in various ways. First of all, leukocyte adhesion to the endothelium can reduce the flow of erythrocytes through microvasculature permeability which causes the phenomenon of brain noreflow and additional brain injury. Proteases, ROS, gelatinase, and collagenase are released by activated leukocytes on the surface of the endothelium damage blood vessels and brain tissue. Activation of phospholipase in leukocytes leads to the release of active substances, such as leukotrienes, eicosanoids, prostaglandins and platelet activating factors, which cause vasoconstriction and prolong platelet aggregation. Finally, infiltrating leukocytes release proinflammatory cytokines and other immune modulators in the penumbra zone that surrounds the infarct core which causes more neuronal injury. ${ }^{9,28}$ 
Table 2 The Comparison of Differential Counts by Risk Factor

\begin{tabular}{|c|c|c|c|}
\hline \multirow[t]{2}{*}{ Variables } & \multicolumn{2}{|c|}{ Risk Factor } & \multirow[t]{2}{*}{$P$ value } \\
\hline & I Risk Factor $(\mathrm{N}=\mid 8)$ & $\geq 2$ Risk Factors $(\mathrm{N}=\mid 75)$ & \\
\hline Leukocyte (cells/uL) & & & 0.276 \\
\hline Mean \pm Std & $9893.33 \pm 2779.528$ & $9279.79 \pm 2842.523$ & \\
\hline Median & 9520.00 & 9080.00 & \\
\hline Range (min-max) & $4880.00-16,830.00$ & $516.00-19,140.00$ & \\
\hline Basophil (\%) & & & 1.00 \\
\hline Mean \pm Std & 0.00 & 0.00 & \\
\hline Median & 0.00 & 0.00 & \\
\hline Range (min-max) & 0.00 & 0.00 & \\
\hline Eosinophil (\%) & & & 0.929 \\
\hline Mean \pm Std & $1.33 \pm 1.236$ & $1.63 \pm 2.166$ & \\
\hline Median & 1.00 & 1.00 & \\
\hline Range (min-max) & $0.00-4.00$ & $0.00-13.00$ & \\
\hline Banded neutrophil (\%) & & & 0.389 \\
\hline Mean \pm Std & $0.16 \pm 0.707$ & $0.03 \pm 0.237$ & \\
\hline Median & 0.00 & 0.00 & \\
\hline Range (min-max) & $0.00-3.00$ & $0.00-2.00$ & \\
\hline Segmented neutrophil (\%) & & & 0.788 \\
\hline Mean \pm Std & $69.16 \pm 11.089$ & $70.01 \pm 12.828$ & \\
\hline Median & 67.50 & 71.00 & \\
\hline Range (min-max) & $45.00-94.00$ & $7.00-93.00$ & \\
\hline Lymphocyte (\%) & & & 0.821 \\
\hline Mean \pm Std & $19.88 \pm 8.137$ & $20.97 \pm 10.126$ & \\
\hline Median & 20.50 & 20.00 & \\
\hline Range (min-max) & $4.00-37.00$ & $4.00-52.00$ & \\
\hline Monocyte (\%) & & & 0.636 \\
\hline Mean \pm Std & $8.94 \pm 6.053$ & $7.08 \pm 2.824$ & \\
\hline Median & 6.50 & 7.00 & \\
\hline Range (min-max) & $2.00-26.00$ & $1.00-25.00$ & \\
\hline
\end{tabular}

In previous studies, proinflammatory cytokine levels were observed to be higher in patients with ischemic stroke in cortical areas. This is presumably due to differences in the cytokine release patterns between the substantia grisea and the substantia alba (gray matter and white matter); in this case, in glia cells and nerve cells. Conversely, other researchers argued that what determines the inflammatory response is the magnitude of the expansion of the infarction. ${ }^{29,30}$

The inflammatory response activated by brain lesions is considered to play a fatal role and trigger secondary brain injuries. The pathophysiological process after stroke onset is known to be caused by leukocyte infiltration and the release of inflammatory mediators. This contributes to neuronal death or apoptosis. Several experiments in mice have shown that increased lymphocytes increases the antiinflammatory regulation of cytokine interleukin (IL) -10 and suppresses proinflammatory cytokines, including IL-6 and tumor necrosis factor (TNF) $-\alpha$, thereby inducing a protective effect on nerves. According to our recent results, low lymphocyte level is associated with poor neurological outcome based on NIHSS scale. Low lymphocyte count is caused by systemic pressure after stroke, which encourages activation of the renin-angiotensin system, resulting in the cortisol release and lymphocyte apoptosis induction. ${ }^{12}$

The type of differential count is affected by the inflammatory process. This process can be assessed by inflammatory markers, including C-reactive protein 
Table 3 The Comparison of Differential Counts by Leukocyte Level

\begin{tabular}{|c|c|c|c|}
\hline \multirow[t]{2}{*}{ Variables } & \multicolumn{2}{|c|}{ Leukocyte Category } & \multirow[t]{2}{*}{$\mathbf{P}$ value } \\
\hline & $>10,000(\mathrm{~N}=66)$ & $\leq 10,000(N=127)$ & \\
\hline Leukocyte (cells/uL) & & & $0.000^{* *}$ \\
\hline Mean \pm Std & $|2,34| .06 \pm 2093.478$ & $7775.85 \pm 1674.718$ & \\
\hline Median & $11,570.00$ & 7970.00 & \\
\hline Range (min-max) & $10,010.00-19,140.00$ & $516.00-10,000.00$ & \\
\hline Basophil (\%) & & & 1.00 \\
\hline Mean \pm Std & 0.00 & 0.00 & \\
\hline Median & 0.00 & 0.00 & \\
\hline Range (min-max) & 0.00 & 0.00 & \\
\hline Eosinophil (\%) & & & 0.071 \\
\hline Mean \pm Std & $1.19 \pm 1.490$ & $1.81 \pm 2.327$ & \\
\hline Median & 1.00 & 1.00 & \\
\hline Range (min-max) & $0.00-6.00$ & $0.00-13.00$ & \\
\hline Banded neutrophil (\%) & & & 0.778 \\
\hline Mean \pm Std & $0.06 \pm 0.387$ & $0.03 \pm 0.264$ & \\
\hline Median & 0.00 & 0.00 & \\
\hline Range (min-max) & $0.00-3.00$ & $0.00-2.00$ & \\
\hline Segmented neutrophil (\%) & & & $0.000^{* *}$ \\
\hline Mean \pm Std & $73.81 \pm 13.405$ & $67.91 \pm 11.799$ & \\
\hline Median & 73.50 & 69.00 & \\
\hline Range (min-max) & $7.00-94.00$ & $29.00-93.00$ & \\
\hline Lymphocyte (\%) & & & $0.00 I^{* *}$ \\
\hline Mean \pm Std & $|7.7| \pm 8.96 \mid$ & $22.51 \pm 10.064$ & \\
\hline Median & 17.50 & 23.00 & \\
\hline Range (min-max) & $4.00-41.00$ & $4.00-52.00$ & \\
\hline Monocyte (\%) & & & 0.855 \\
\hline Mean \pm Std & $7.43 \pm 3.791$ & $7.16 \pm 2.994$ & \\
\hline Median & 7.00 & 7.00 & \\
\hline Range (min-max) & $1.00-26.00$ & $2.00-25.00$ & \\
\hline
\end{tabular}

Note: **Mann-Whitney test significance at $\mathrm{p}<0.00 \mathrm{I}$.

(CRP) and erythrocyte sedimentation rate (ESR). ${ }^{31} \mathrm{We}$ did not have the data about CRP and ESR. Therefore, these two markers are better studied in the future research.

In this study, we have several limitations. There is an absence of data related to infarct volume on head CT scans. The study has no control nor knowledge over when the blood samples were harvested in the events post stroke. We report the types of risk factors not in the form of an average value of each of these factors. All these mitigating factors could have led to confounders in the research. This retrospective study only provided a glimpse of the importance of the lymphocyte count in the pathogenesis of ischemic stroke. As a follow up, we could design our own research trial and harvest fresh blood from new subjects to confirm our hypothesis.

\section{Conclusions}

This study showed that the decrease of lymphocyte count in patients with leukocytosis is associated with poor NIHSS scores. This suggests that lymphocyte count can be used as an indicator of inflammation in acute ischemic stroke patients and as a predictor of neurological outcome after an ischemic stroke. 
Table 4 Comparison Between Differential Counts by Location of Infarction

\begin{tabular}{|c|c|c|c|c|}
\hline \multirow[t]{2}{*}{ Variables } & \multirow[b]{2}{*}{ Subcortical $(N=\mid 56)$} & \multicolumn{2}{|l|}{ Infarct Location } & \multirow[t]{2}{*}{$P$ value } \\
\hline & & Cortical (N=22) & Pons $(\mathrm{N}=15)$ & \\
\hline Leukocyte (cells/uL) & & & & 0.877 \\
\hline Mean \pm Std & $9287.93 \pm 2463.710$ & $98|2.27 \pm 4| 09.448$ & $9150.40 \pm 4159.565$ & \\
\hline Median & 9095.00 & 9705.00 & 9000.00 & \\
\hline Range (min-max) & $3230.00-18,120.00$ & $2540.00-19,140.00$ & $516.00-18,980.00$ & \\
\hline Basophil (\%) & & & & 1.00 \\
\hline Mean \pm Std & 0.00 & 0.00 & 0.00 & \\
\hline Median & 0.00 & 0.00 & 0.00 & \\
\hline Range (min-max) & 0.00 & 0.00 & 0.00 & \\
\hline Eosinophil (\%) & & & & 0.925 \\
\hline Mean \pm Std & $1.67 \pm 2.226$ & $1.36 \pm 1.559$ & $1.26 \pm 1.222$ & \\
\hline Median & 1.00 & 1.00 & 1.00 & \\
\hline Range (min-max) & $0.00-13.00$ & $0.00-5.00$ & $0.00-4.00$ & \\
\hline Banded neutrophil (\%) & & & & 0.546 \\
\hline Mean \pm Std & $0.05 \pm 0.345$ & 0.00 & 0.00 & \\
\hline Median & 0.00 & 0.00 & 0.00 & \\
\hline Range (min-max) & $0.00-3.00$ & 0.00 & 0.00 & \\
\hline Segmented neutrophil (\%) & & & & 0.278 \\
\hline Mean \pm Std & $69.35 \pm 12.028$ & $70.72 \pm 17.989$ & $74.73 \pm 8.883$ & \\
\hline Median & 70.00 & 72.50 & 72.00 & \\
\hline Range (min-max) & $29.00-94.00$ & $7.00-90.00$ & $62.00-90.00$ & \\
\hline Lymphocyte (\%) & & & & 0.356 \\
\hline Mean \pm Std & $21.23 \pm 10.073$ & $17.95 \pm 9.805$ & $21.46 \pm 8.559$ & \\
\hline Median & 20.00 & 16.00 & 20.00 & \\
\hline Range (min-max) & $4.00-52.00$ & $5.00-36.00$ & $10.00-41.00$ & \\
\hline Monocyte (\%) & & & & 0.316 \\
\hline Mean \pm Std & $7.16 \pm 3.287$ & $7.90 \pm 3.084$ & $7.26 \pm 3.594$ & \\
\hline Median & 7.00 & 8.00 & 6.00 & \\
\hline Range (min-max) & $1.00-26.00$ & $2.00-15.00$ & $2.00-17.00$ & \\
\hline
\end{tabular}

Table 5 Correlation Between NIHSS Degree Score at Admission, NIHSS Degree Score at Discharge, and Abnormal Differential Count

\begin{tabular}{|l|l|l|}
\hline Variables & NIHSS Degree Score at Admission & \multicolumn{1}{|c|}{ NIHSSA Degree at Discharge } \\
\hline Leukocyte & $R=0.018, P$ value $=0.886$ & $R=0.015 P$ value $=0.905$ \\
\hline Basophil & $R=-0.165 P$ value $=0.572$ & $R=-0.112 P$ value $=0.702$ \\
\hline Eosinophil & $R=0.019 P$ value $=0.796$ & $R=0.05 P$ value $=0.49$ \\
Banded neutrophil & $R=-0.143 P$ value $=0.217$ & $R=-0.104 P$ value $=0.37 I$ \\
Segmented neutrophil & $R=0.245 P$ value $=0.033^{*}$ & $R=0.189 P$ value $=0.102$ \\
Lymphocyte & $R=0.039 P$ value $=0.785$ & $R=0.003 P$ value $=0.985$ \\
Monocyte &
\end{tabular}

Notes: R: correlation coefficient, *Significance at $p<0.05$. 


\section{Acknowledgments}

We would like to thank all the staff members of Hasan Sadikin Hospital for their contribution during data collection and University of Padjadjaran for providing ethical clearance.

\section{Disclosure}

Dr Nur Atik reported grants from Universitas Padjadjaran during the conduct of the study. The authors reported no other potential conflicts of interest for this work.

\section{References}

1. Mir MA, Al-Baradie SR, Malik D, Alhussainawi DM. Pathophysiology of stroke. In: Mir MA, editor. Recent Advances in Stroke Therapeutics. 1st ed. Nova Science Publishers, Inc; 2014:25-80.

2. Liu R, Pan MX, Tang JC, et al. Role of neuroinflammation in ischemic stroke. Neuroimmunol Neuroinflamm. 2017;4(8):158-166. doi: $10.20517 / 2347-8659.2017 .09$

3. Adams HP Jr, Biller J. Classification of subtypes of ischemic stroke: history of the trial of org 10172 in acute stroke treatment classification. Stroke. 2015;46(5):e114-7. doi:10.1161/ STROKEAHA.114.007773

4. Nam KW, Kwon HM, Jeong HY, Park JH, Kim SH, Jeong SM. High neutrophil to lymphocyte ratios predict intracranial atherosclerosis in a healthy population. Atherosclerosis. 2018;269:117-121. doi:10.1016/j.atherosclerosis.2017.035

5. Meder R, Świtońska M, Płeszka P, Palacz-Duda V, Dzianott-Pabijan D, Sokal P. Endovascular treatment of stroke caused by carotid artery dissection. Brain Sci. 2020;10(11):800. doi:10.3390/brainsci10110800

6. Wilck N, Ludwig A. Targeting the ubiquitin-proteasome system in atherosclerosis: status quo, challenges, and perspectives. Antioxid Redox Signal. 2014;21(17):2344-2363. doi:10.1089/ars.2013.5805

7. Wang Z, He D, Zeng YY, et al. The spleen may be an important target of stem cell therapy for stroke. J Neuroinflamm. 2019;16(1):1-24. doi:10.1186/s12974-019-1400-0

8. Siniscalchi A, Gallelli L, Malferrari G, et al. Cerebral stroke injury: the role of cytokines and brain inflammation. J Basic Clin Physiol Pharmacol. 2014;25(2):131-137. doi:10.1515/jbcpp-2013-0121

9. Kim JY, Park J, Chang JY, Kim SH, Lee JE. Inflammation after ischemic stroke: the role of leukocytes and glial cells. Exp Neurobiol. 2016;25(5):241. doi:10.5607/en.2016.25.5.241

10. Zhang J, Ren Q, Song Y, et al. Prognostic role of neutrophil-lymphocyte ratio in patients with acute ischemic stroke. Medicine. 2017;96:45. doi:10.1097/MD.0000000000008624

11. Bolayır A. The relationship between lymphocyte/monocyte ratio and short-term mortality in acute ischemic stroke patients. Cumhuriyet Tip Dergisi. 2018;40(2):128-134. doi:10.7197/223. v40i37154.410205

12. Ren H, Liu X, Wang L, Gao Y. Lymphocyte-to-monocyte ratio: a novel predictor of the prognosis of acute ischemic stroke. J Stroke Cerebrovasc Dis. 2017;26(11):2595-2602. doi:10.1016/j. jstrokecerebrovasdis.2017.06.019

13. Kwakkel G, Veerbeek JM, van Wegen EE, Nijland R, Harmeling-van der Wel BC, Dippel DWJ. Predictive value of the NIHSS for ADL outcome after ischemic hemispheric stroke: does timing of early assessment matter? J Neurol Sci. 2010;294(1-2):57-61. doi:10.1016/j.jns.2010.04.004

14. Ghose SK, Ahmed KGU, Chowdhury AH, Hasan ATMH, Saha K, Mahmud R. Assesment of initial stroke severity by National Stroke Institute Stroke Scale (NIHSS) score at admission. J Dhaka Med Coll. 2017;26(2):90-93. doi:10.3329/jdmc.v26i2.38765
15. Elsaid RAA, Sliman AMA, Gilmartin H, El-Hajj D, Battaglia C. Physiological parameters deterioration in acute stage after stroke: rehabilitation versus conventional care. J Nurs Educ Pract. 2020;10 (3). doi:10.5430/jnep.v10n3p79

16. Caplan LR, Liebeskind DS. Caplan's Stroke a Clinical Approach. 5th ed. Cambridge University Press; 2016:19-54, 312-363.

17. Sacco RL, Kasner SE, Broderick JP, et al. An updated definition of stroke for the 21st century: a statement for healthcare professionals from the American Heart Association/American Stroke Association. Stroke. 2013;44(7):2064-2089. doi:10.1161/STR0b013e318296aeca

18. Halkes PHA, Kappelle LJ, Van Gijn J, van Wijk I, Koudstaal PJ, Algra A. Large subcortical infarcts. Clinical features, risk factors and long-term prognosis compared with cortical and small deep infarcts. Stroke. 2006;37(7):1828-1832. doi:10.1161/01.STR.000022 6993.88307

19. Gąsiorek A, Banach B, Maciejewski M, Głąbiński A, Aleksandra Paduszyńska A, Dąbrowa AB. Stroke as a result of cardioembolism - characteristic features in the context of diagnostic methods and secondary prevention. Folia Cardiol. 2018;13(1):21-28. doi:10.5603/FC.2018.0004

20. Arboix A, Alio J. Cardioembolic stroke: clinical features, specific cardiac disorders and prognosis. Curr Cardiol Rev. 2010;6 (3):150-161. doi:10.2174/157340310791658730

21. Powers WJ, Rabinstein AA, Ackerson T, et al. Guidelines for the early management of patients with acute ischemic stroke a guideline for healthcare professionals from the American Heart Association/ American Stroke Association. Stroke. 2018;49(3):e46-e110. doi:10.1161/STR.0000000000000158

22. Yaghi S, Mitchell SV, Elkind MSV. Lipids and cerebrovascular disease research and practice. Stroke. 2015;46(11):3322-3328. doi:10.1161/STROKEAHA.115.011164

23. Renna NF, De Las Heras N, Miatello RM. Pathophysiology of vascular remodeling in hypertension. Int J Hypertens. 2013;2013. doi: $10.1155 / 2013 / 808353$

24. Raggi P, Genest J, Giles JT, et al. Role of inflammation in the pathogenesis of atherosclerosis and therapeutic interventions. Atherosclerosis. 2018;276(276):98-108. doi:10.1016/j. atherosclerosis.2018.07.014

25. Virella G, Lopes MF. The role of the immune system in the pathogenesis of diabetic complications. Front Endocrinol. 2014;5 (126):1-2. doi:10.3389/fendo.2014.00126

26. Maestrini I, Strbian D, Gautier S, et al. Higher neutrophil counts before thrombolysis for cerebral ischemia predict worse outcomes. Neurology. 2015;85(16):1408-1416. doi:10.1212/ WNL.0000000000002029

27. Baehr M, Frotscher M. Blood supply and vascular disorders of the central nervous system. In: Duus' Topical Diagnosis in Neurology. Anatomy, Physiology, Signs, Symptoms. 5th ed. Georg Thieme Verlag; 2012:270-278.

28. Świtońska M, Piekuś-Słomka N, Słomka A, Sokal P, Żekanowska E, Lattanzi S. Neutrophil-to-lymphocyte ratio and symptomatic hemorrhagic transformation in ischemic stroke patients undergoing revascularization. Brain Sci. 2020;10(11):771. doi:10.3390/ brainsci10110771

29. Vila N, Castillo J, Dávalos A, Chamorro A. Proinflammatory cytokines and early neurological worsening in ischemic stroke. Stroke. 2000;31(10):2325-2329. doi:10.1161/01.str.31.10.2325

30. Vila N, Castillo J, Dávalos A, Esteve A, Planas AM, Chamorro Á. Levels of anti-inflammatory cytokines and neurological worsening in acute ischemic stroke. Stroke. 2003;34(3):671-675. doi:10.1161/01. STR.0000057976.53301.69

31. Watson J, Jones HE, Banks J, Whiting P, Salisbury C, Hamilton W. Use of multiple inflammatory marker tests in primary care: using clinical practice research datalink to evaluate accuracy. $\mathrm{Br} J$ Gen Pract. 2019;69(684):e462-9. doi:10.3399/bjgp19X704309 


\section{Publish your work in this journal}

The International Journal of General Medicine is an international, peer-reviewed open-access journal that focuses on general and internal medicine, pathogenesis, epidemiology, diagnosis, monitoring and treatment protocols. The journal is characterized by the rapid reporting of reviews, original research and clinical studies across all disease areas. The manuscript management system is completely online and includes a very quick and fair peer-review system, which is all easy to use. Visit http://www.dovepress.com/ testimonials.php to read real quotes from published authors.

Submit your manuscript here: https://www.dovepress.com/international-journal-of-general-medicine-journal 